\title{
Antimicrobial susceptibility test of pathogens isolated from urinary tract infection suspected cases
}

\author{
Yadav K, Prakash S, Serayi RC, Shilpkar T, Shrestha S \\ Department of Microbiology, National Institute of Science and Technology, Kathmandu, Nepal
}

\begin{abstract}
Background and objectives: Urinary tract infection (UTI) is associated with multiplication of organisms in urinary tract and is defined by the presence of more than $10^{5}$ organisms per $\mathrm{ml}$ in a midstream sample of urine (MSU). UTI is most commonly acquired bacterial infection in ambulatory and hospitalized populations. E.coli is the most predominant organism to colonise the urethral meatus and perineum before ascending to the bladder. Drug resistance of pathogens is a serious medical problem, because of very fast arise and spread of mutant strains that are insusceptible to medical treatment of UTI. Therefore, this study was carried out to determine the common pathogenic bacteria causing UTI and to determine their antibiotic susceptibility pattern.

Material and Methods: Mid stream urine samples of the UTI suspected pateints were collected in the Mid Stream Urine (MSU) samples were collected in the sterile clean dry wide mouthed bottle. Standard protocol was followed to isolate and identify organism which was followed by disc diffusion antibiotic sensitivity tests.
\end{abstract}

Results: A total of 100 samples were collected. Out of 100 samples, 25 samples showed a significant growth E.coli, Citrobacter diversus, Klebsiella pneumoniae, Staphylococcus aureus were isolated. E.coli (84\%) was found to be the most prevalent causing UTI.

Conclusion: UTI was found more common in female than male and E.coli was found to be main causes of UTI. Ciprofloxacin showed more effective drugs in the treatment of UTI.

Key words: Ciprofloxacin, Disc diffusion, Mid Stream Urine, UTI

\section{INRODUCTION}

UTI is associated with multiplication of organisms in urinary tract and is defined by the presence of more than $10^{5}$ organisms per $\mathrm{ml}$ in a midstream sample of urine (MSU). UTI encompasses a wide variety of clinical entities whose common denometer is microbial invasion of any tissue of the urinary tract from the renal cortex to the urethral meatus [1]. Urinary tract infection (UTI) is not only a common in outpatient affliction, but also the most frequently occurring nosocomial infection [2, 3] followed by catherization and gynecological surgery.

Significant bacteriuria is lacking in some cases of true UTI, especially in symptomatic 
patients, a smaller number of bacteria $\left(10^{2}\right.$ to $10^{4} / \mathrm{mL}$ ) may signify infection. In urine specimens obtained by suprapubic aspiration or "in-and-out" catheterization and in samples from a patient with an indwelling catheter, colony counts of $10^{2}$ to $10^{4} / \mathrm{mL}$ generally indicate infection. Conversely, colony counts of $>10^{5} / \mathrm{mL}$ of midstream urine are occasionally due to specimen contamination, which is especially when multiple species are found [4].

Prevalence of infection allied directly with age, increasing from about $1 \%$ to $6 \%$ between puberty and 60 years. The vast majority of uncomplicated UTIs are caused by the Gramnegative bacilli and Escherichia coli are the most common cause of UTI, and with other pathogens including Enterococci, Staphylococcus saprophyticus, Klebsiella spp, Pseudomonas spp, Proteus spp, klebsiella spp, and Staphylococcus aureus and Proteus mirabilis [5]. Infection due to Proteus spp is associated with renal stones while Staphylococcus saprophyticus infections are usually found in sexually active women. Majority of UTIs are not life threatening but when the kidneys are involved, there is risk of permanent tissue damage with an increased risk of bacteremia [6]. Neonates, girls, young women, and older men are mainly vulnerable to UTIs. Bacterial cystitis infection are much more common in women which is considered as morbidity and account for $1.2 \%$ of all consultations in general practice. Every woman has a $60 \%$ lifetime risk of developing bacterial cystitis, which develops mostly before the age of 24[7]. The structure of the females urethra and vagina makes it susceptible to trauma during sexual intercourse as well as bacteria been massaged up the urethra and into the bladder during pregnancy and or child birth $[8,9]$. By contrast, men have a lifetime risk of only $13 \%$
[7]. In children approximately $5 \%$ of girls and $1 \%$ of boys have a UTI by 11 years of age [10].

Each year, UTIs accounts for about seven million office visits and another one million emergency department visits, resulting in about 100,000 hospitalizations [11]. It is estimated that 150 million cases of UTI occur on a global basis per year resulting in more than 4 billion pounds in direct health care expenditure [12]. According to annual report of Fiscal year (2059/2060) published by Department of Health Service, Morbidity of UTI in Nepal was 1, 25,058. Geograpical distribution of UTI among the Nepalese population is 13,518 in the mountains, 58,858 in Hills and 42,682 in Terai. At the beginning of $20^{\text {th }}$ century, mortality upto $20 \%$ was reported among infants and neonates hospitalized for acute pyelonephritis [13].

The extensive and inappropriate use of antimicrobial agents has invariably resulted in the development of antibiotic resistance which, in recent years, has become a major problem in worldwide because infection caused by MDR strains (the strain showed resistance to three or more antibiotics among the six commonly precribed drugs) often lead to death [14]. In patients with suspected UTI, antibiotic treatment is usually started empirically, before urine culture results are available. To ensure appropriate treatment, knowledge of the organisms that cause UTI and their antibiotic susceptibility is mandatory [15]. Therefore, this present study aims to isolate and identify the bacteria in the patients suspected of UTI, to determine the trend of their antimicrobial susceptibilty and the status of multi-drug resistance organism causing UTI.

\section{MATERIALS AND METHODS}


This study was conducted at Microbiology Department of National College, khushibu, Nayabazar, Kathmandu. Urine samples of suspected patients of UTI were collected during the period of 2069/03/05 to 2069/03/12 from Nepal Police Hospital, Lazimpat, Kathmandu, Nepal and TU Teaching hospital, Maharajgunj, Kathmandu, Nepal. The Mid Stream Urine (MSU) samples were collected in the sterile clean dry wide mouthed bottle.The distinctive instruction was followed by the patient for the sample collection. The samples were immediately transported to Microbiology Department of National College. Media were prepared as instructed by the manufacturer company (Himedia). The specimen were cultured into the Mac Conkey Agar (MA) and Blood Agar (BA) by the Semi-Quantitative method and incubated at $37^{\circ} \mathrm{C}$ for 24 hours for isolation. The significant growth of isolates were subcultured on Nutrient Agar (NA) and incubated at $37^{\circ} \mathrm{C}$ for 24 hours. This was followed by Gram's staining and biochemical tests were performed according to Gram's staining results for identification. Antibiotic sensitivity test for the isolated organism were done by using Kirby Bauer Disc Diffusion Method following the definition of the National Committee of Clinical Laboratory Standards [14]. Bacterial inoculums were prepared by suspending the freshly-grown bacteria in 25 mL sterile Nutrient broth. A sterile cotton swab was used to streak the surface of Mueller Hinton agar plates. Filter paper disks containing designated amounts of the antimicrobial drugs obtained from commercial supply firms (Himedia Labs, Mumbai, India) were used. Interpretation as 'Sensitive' or 'Resistant' was done on the basis of the diameters of zones of inhibition of bacterial growth as recommended by the disc manufacturer.

\section{RESULTS}

A total of 100 samples were collected. Out of 100 samples, 25 samples showed a significant growth. Among them 12 were males and 13 were females patients. About $44 \%$ samples were from the patients of the age group ranging 30-40 years and 24\% samples from the patients of age group 20-30 years and further are as shown in table 1 :

Table1: Age and gender wise distribution

\begin{tabular}{|l|c|c|c|c|}
\hline $\begin{array}{l}\text { Age } \\
\text { group } \\
\text { (yrs) }\end{array}$ & Male & Female & Total & $\begin{array}{c}\text { Percent } \\
\text { (\%) }\end{array}$ \\
\hline $20-30$ & 3 & 3 & 6 & $24 \%$ \\
\hline $30-40$ & 2 & 9 & 11 & $44 \%$ \\
\hline $40-50$ & 1 & 1 & 2 & $8 \%$ \\
\hline $50-60$ & 2 & 0 & 2 & $8 \%$ \\
\hline $60-70$ & 2 & 0 & 2 & $8 \%$ \\
\hline $70-80$ & 2 & 0 & 2 & $8 \%$ \\
\hline
\end{tabular}

Out of 100 samples, 25 (25\%) showed significant growth of $10^{5} \mathrm{cfu} / \mathrm{ml}$ while the 75 samples didn't show the significant growth.

Out of 25 samples showing significant bacteriuria 21 (84\%) were caused by E. coli whereas $4(16 \%)$ were caused by Citrobacter diversus, Klebsiella pneumoniae, and Staphylococcus aureus.

Antibiotic susceptibility pattern of isolated microorganism is presented in table 2 . Out of 21 E.coli isolates, $47.6 \%$ isolates were sensitive towards Ciprofoxacin and Cefixime. $33 \%$ were sensitive towards Nitrofurantoin. Similarly, $76.19 \%$ were resistance towards Amoxicillin and $52.38 \%$ were resistance towards Amikacin. 
Table 2: Antibiotic Susceptibility Pattern of isolated microorganism.

\begin{tabular}{|l|c|c|c|l|c|}
\hline \multirow{2}{*}{ Isolates } & \multicolumn{5}{|c|}{ Antimicrobial agents } \\
\cline { 2 - 6 } & Amoxycillin & Nitrofurantoin & Amikacin & Ciprofloxacin & Cefixime \\
\hline E.coli & $\mathrm{R}$ & $\mathrm{S}$ & $\mathrm{R}$ & $\mathrm{S}$ & $\mathrm{S}$ \\
\hline C.diversus & $\mathrm{I}$ & $\mathrm{I}$ & $\mathrm{S}$ & $\mathrm{S}$ & $\mathrm{I}$ \\
\hline $\begin{array}{l}\text { K. } \\
\text { pnemoniae }\end{array}$ & $\mathrm{R}$ & $\mathrm{S}$ & $\mathrm{I}$ & $\mathrm{S}$ & $\mathrm{S}$ \\
\hline S.aureus & $\mathrm{R}$ & $\mathrm{I}$ & $\mathrm{R}$ & $\mathrm{R}$ & $\mathrm{R}$ \\
\hline
\end{tabular}

$\mathrm{R}=$ Resistant; $\mathrm{S}=$ Sensitive

Similarly, Citrobacter diversus was found to be sensitive towards Amikacin and Ciprofloxacin whereas it was found to be intermediate towards Nitrofurantoin, Cefixime and Amoxicillin.

Out of two Klebsiella pneumoniae isolated $100 \%$ were found to be sensitive towards Nitrofurantoin, Cefixime and Ciprofloxacin. They were found to be $100 \%$ resistance to Amoxicillin but $50 \%$ of them intermediate to Amikacin.

Staphylococcus aureus was found to be resistant towards Amikacin, Ciprofloxacin, Cefixime and Amoxicillin but was found intermediate towards Nitrofuramtoin.

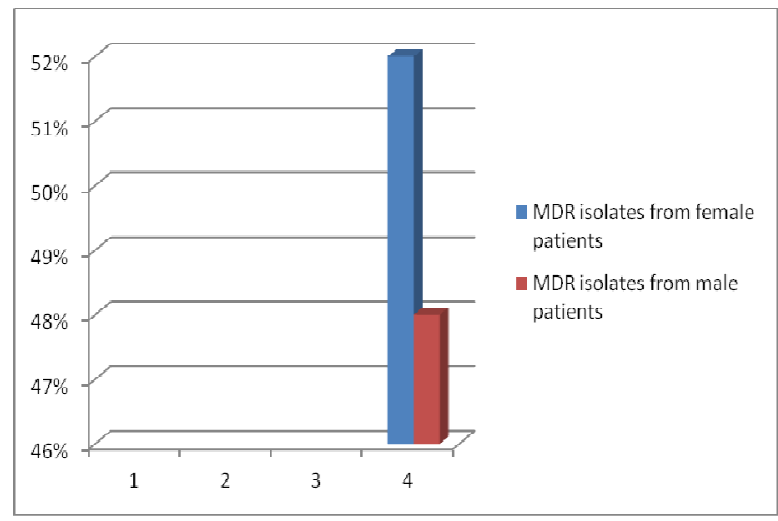

Fig 1: Genderwise distribution of total isolates and MDR isolates.
Out of 25 organisms isolated, $52 \%$ were found to be MDR isolates. Among them 52\% of MDR isolates were from female and $48 \%$ isolates from male patients.

\section{DISCUSSION}

In community and hospital settings the etiology of UTIs and the antimicrobial susceptibility of UTI causing bacteria's have been changing over the years [ 17,18]and accounts for the significant morbidity and high medical costs. The prevalence rate is highly influenced by gender and increasing age and being most common among females. The high prevalence rate in females is markedly relied upon the short ureter (i.e, $4 \mathrm{~cm}$ ) [9]. In this study, out of growth positive samples, $12(48 \%)$ were in males and 13 (52\%) were in females which shows female with high prevalance of UTI. Out of growth positive samples, $44 \%$ were from the patients of the age group ranging from 30-40 years and $24 \%$ from the age group 20-30 years. While the study conducted by Central Deparment of Microbiology, kirtipur [19], age group of 20-30 showed maximum growth $(66.67 \%)$ among total positive cases. This study showed high growth positivity in the 
age group 30-40 which may be due to the higher number of growth positive samples from female patients or may be due to ignorance and poor hygienic practices.

A summary of the different microorganisms isolated during the study period is shown in fig 2. It is clear that $E$. coli was the predominant uropathogen (84\%) causing UTI, followed by Staphylococcus aureus, Klebsiella pneumonia and Citrobacter diversus of about $16 \%$ were the least dominant uropathogen causing UTI. The findings of this study compared favorably with the similar study carried out by the Department of Microbiology, Amrit Science Campus, Kathmandu; Central Department of Microbiology, TU, Kirtipur and Lumbini Zonal Hospital, Butwal (2009) and Shrestha R, National College (2008)(19,20) showed growth positively of $45 \%$ of which $55.5 \%$ were Gram negative bacteria and 52.2\% repectively. These observations were supported by several studies conducted previously. Reports indicate E. coli as the most common organism (64.3\%), followed by S. aureus (21.4\%) and Klebsiella pneumoniae (14.3\%). Of them E.coli was the most common pathogens isolated [21, 22]. This study also showed maximum E.coli isolates i.e, 84\% which may be due to the urinary tract is the most common site of E.coli infection, and more than $90 \%$ of all uncomplicated UTIs are caused by E.coli infection.

The recurrence rate after a first E.coli infection is $44 \%$ over 12 months which is the most predominant organism to colonise urethral meatus and perineum before ascending to the bladder which produces vast array of virulence factor causing UTI. Pathogenic E.coli expresses specific adhesion such as $\mathrm{P}$ fimbriae and produces alpha and beta haemolysins which are cytotoxic due to formation of transmembrane pores in host cells. E.coli causes a wide range of UTIs, including uncomplicated urethritis, cystitis, symptomatic cystitis, pyelonephritis, acute prostatis, prostatic abscess, and urosepsis $[22,26]$.

Over the last decade, the treatment of choice of drug for urinary tract infections (UTIs) has changed from co-trimoxazole to quinolones owing to the rate of resistance to cotrimoxazole and its high level of therapeutic failure [23]. Antimicrobial resistance has been associated with an increased rate of clinical failure, and reports from Canada and the US indicate that the prevalence of cotrimoxazole resistance exceeds $15 \%$ and can be as high as $25 \%$. Use of fluoroquinolones is recommended for uncomplicated UTIs in areas where the incidence of cotrimoxazole resistance exceeds $10 \%$, as well as for the treatment of complicated UTIs and acute pyelonephritis $[23,24,25]$.

This study found that the most of the stains (52\% of the isolates) were susceptible to Ciprofloxacin; whereas $52 \%$ of the isolates were susceptible to cefixime also found that $76 \%$ of the isolates were resistant against Amoxicillin followed by resistant against Amikacin and $48 \%$ resistant against Ciprofloxacin while similar study carried out by Amatya, et. al at B.P. Koirala Institude of Health Sciences, Dharan showed that out of 81 isolates taken from the operative UTI cases of E.coli isolates, 92\% showed resistant to Ampicillin, $77 \%$ showed resistant to Ciprofloxacin, 30\% showed resistance to Amikacin [26]. The percentage of sensitivity of Ciprofloxacin in this study was high because we had no selection in sample 
collection whereas in the latter study, the samples were taken from the post operative UTI cases.

This study found that out of 25 isolates, 52\% were found to be MDR isolates. Among them $61.5 \%$ of MDR isolates were from female and $38.5 \%$ isolates were from male patients who may be due to high level of poverty, ignorance and poor hygienic practices, and also due to high prevalence of fake and spurious drugs of questionable quality in circulation. Most of the isolates were resistant to four or more antibiotics which may be due to plasmid carrying drug resistance genes occuring in many bacteria $[27,28]$.

\section{CONCLUSION}

Chronic or acute infections of urinary tract may cause high blood pressure, kidney damage, uremia or death. In some instances the infections are in apparent and may go unseen for sometime, most infections of this tract enter by way of urethra; very few originate in the blood which causes mortality and morbidity in the world affecting all age groups across the life span. So this study was conducted to determine the common pathogenic bacteria causing UTI and to determine their antibiotic susceptibility pattern. The susceptibility and resistance profile of all isolates in this study have shown that the higher efficacy possesses by Ciprofloxacin while Nitrofurantoin, Cephalexin possess lower efficacy. Despite this efficacy, there was a general increase in the resistance pattern of isolates to all the antibiotics used in this study. The present study confirms that bacterial resistance would be a greatest problem in the country. The findings of the present study confirms that still some bacteria are resistant to antibiotics especially Amoxicillin, Amikacin and Ciprofloxacin, frequently used drugs in many parts of the world which helps to be addressed to policy makers to formulate a srtict antibiotic prescription policy for the treatment of UTI for human welfare.

\section{ACKNOWLEDGEMENT}

Authors wish Authors wish to thank Mrs. Sarita Manandhar, Head of Department (Microbiology), and Mrs.Nisha Puri, NIST College, Kathmandu for their support in carrying out the research.

\section{REFERENCES}

1. Pokhrel BM, Koirala J, Mishra SK, Dahal RK, Khadga P, Tuladhar NR. Multidrug resistance and extended spectrumbetalactamase producing strains causing lower respiratory tract and urinary tract infection. Int. J. Med. Sci. 2006; 28(3):19-27.

2. Wagenlehner FM, Naber KG, Weidner W (2008) Rational antibiotic therapy of urinary tract infections. Med Monatsschr Pharm, 2008: 31: 385-90.

3. Siddiqui AA (2008) Prevalence of quinoloneresistant urinary tract infections in Comanche County Memorial Hospital. J Okla State Med Assoc 101: 210-12.

4. Stamm WE, Schaeffer AJ. The State of the Art in the management of Urinary Tract Infections. Am J Med 2002; (suppl 1 A): 113.

5. Blondeau JM. Current issues in the management of urinary tract infections: extended-release ciprofloxacin as a novel treatment option. Drugs. 2004; 64(6): 611-28.

6. Hvidberg, H., C. Struve, K.A. Krogfelt, N. Christensen, S.N. Rasmussen and N. Frimodt-M ler, 2000. Development of a long-term ascending urinary tract infection mouse model for antibiotic treatment studies. Antimicrob. Agents Chemother., 44:156-163.

7. Nicole W, Jon DM. Deciphering Dysuria. Emerg Med. 2008; 40(9): 29.

8. El-Sweih, N., W. Jamal and Rotimi Vo, Spectrum and antibiotic resistance of uropathogens isolated from hospital and 
community patients with urinary tract infections in two large hospitals in Kuwait, 2008;14:401-407

9. Kolawale, A.S., Kolawale, O.M., KandakiOlukemi, Y.T., Babatunde, SK, Durowade KA, Kplawale CF; Prevalence of urinary tract infections among patients attending Dalhatu Araf Specialist Hospital, Lafia, Nasarawa state, Nigeria. 2009; Int. J. Med. Sci.1(5):163-167

10. Jenson BH, Baltimore RS. Infectious Diseases. Nelson Essentials of Pediatrics 5th edition. Elsevier Inc. 2006; p.522.

11. Ferry, SA.L.G. Burwan and B. Mattson, Urinary tract infection in health care in Northern Sweden, I. Epidemilogy Scand Infect Des.36; 1987; 296-301.

12. Jackson E. Flower J.R. Urinary Tract and Inflammation, Year book Medical Publishers, INC 1990;

13. New HC. Urinary tract infections. Am J Med. 1996; 100 (Suppl.4A): S63-70.

14. Goldstein FW. Antibiotic susceptibility of bacterial strains isolated from patients with community-acquired urinary tract infections in France. Multicentre Study Group. Eur J Clin Microbiol Infect Dis. 2000; 19:112-7.

15. Ashkenazi S, EvenTov S, Samra Z, et al. Uropathogens of various childhood populations and their antibiotic susceptibility. Pediatr Infect Dis J. 1991; 10: 742-6.

16. New HC. Urinary tract infections. Am J Med. 1996; 100 (Suppl.4A): S63-70.

17. Jones RN. Impact of changing pathogens and antimicrobial susceptibility pattern in treatment of serious infections in hospitalized patients. Am J Med. 1996; 100 (Suppl.6A): S312

18. Department of Microbiology, Amrit Science Campus, kathmandu, Central Department of Microbiology, TU kirtipur, Lumbini Zone Hospital, Bhutwal, J Health Research Council 2009; Oct (15); 82-83.

19. Chaudhary R, Ojha1 CR, Sijapati K, Singh SK. Bacterial Pathogen Responsible For Urinary Tract Infection, 2012; 11(1): 19

20. Bours PH, Polak R, Hoepelman AI, et al. Increasing resistance in community-acquired urinary tract infections in Latin America, five years after the implementation of national therapeutic guidelines. Int J Infect Dis. 2010; 14(9):

21. Goswami, R., C.S. Bal, S. Tejaswi, G.V. Punjabi and N. Kochupillai,. Prevalence of urinary tract infection and renal scars in patients with diabete mellitus. Diabetes Res. Clin. Pract. 2001, 53(3): 181-186

22. Yilmaz K, Nilay C, Aysegül G, et al. Cotrimoxazole and quinolone resistance in Escherichia coli isolated from urinary tract infections over the last 10 years. International J Antimicrbial Agents. 2005; 26 (1): 75-77.

23. Chaniotaki S, Giakouppi P, Tzouvelekis LS, Panagiotakos D, community acquires urinary tract infections in Greece. Clin. Microb, Infection; 2004 1:75-8.

24. Miller, L.G., et. al. Treatment of uncomplicated urinary tract infections in an era of increasing antimicrobial resistance. Mayo Clin Proc. 2004; 79(8); 1048-54.

25. Gupta, K., et. al. Patient-initiated treatment of uncomplicated recurrent urinary tract infections in young women. Ann Intern Med. 2001; 135: 9-16.

26. Shrestha R, Gyawali N, Gurung R, R Amatya, .Bhattacharya S .K Effect of urogenital cleaning with paper soap on bacterial contamination rate while collecting midstream urine specimens. Journal of laboratory physician 2013; 5: 17-20.

27. Shalini, Joshi MC, Rashid MK, Joshi HS. Study of Antibiotic Sensitivity Pattern in Urinary Tract Infection at a Tertiary Hospital. NJIRM 2011: 2(3):43-46.

28. Borderon, E and T. Horodniceanu metabolically deficient dwarf colon mutants of E.coli: deficiency and resistance to antibiotics of strains isolated from urine culture. J. Clin. Microbial. 8; 1978. 629-634.

\section{Correspondence to:}

Khushbu Yadav

National Institute of Science and Technology, Kathmandu E-mail: meetkhushi20@gmail.com 